\title{
Mixed response on regorafenib treatment for GIST (gastro-intestinal stromal tumor) according to ${ }^{18} \mathrm{~F}-\mathrm{FDG}-\mathrm{PET} / \mathrm{CT}$
}

\author{
Donatienne Van Weehaeghe ${ }^{1 *}$ (D), Olivier Gheysens ${ }^{1}$, Vincent Vandecaveye ${ }^{2}$, Patrick Schöffski ${ }^{3}$, Koen Van Laere ${ }^{1}$
} and Christophe M. Deroose ${ }^{1}$

\begin{abstract}
Background: Gastro-intestinal stromal tumors (GISTs) are very rare tumors of the gastro-intestinal tract, originating from the interstitial cells of Cajal or a common cell precursor which both express type III tyrosine kinase receptors. Regorafenib is an oral multi-kinase inhibitor used to treat gastro-intestinal stromal tumors. To our knowledge this is the first case in literature to show the response of regorafenib on PET.

Case presentation: A 37-year-old male with lower abdominal pain and weight loss was referred to our hospital. Abdominal ultrasound and computed tomography (CT) showed diffuse peritoneal implants. Surgical specimen histology showed a GIST with c-KIT exon 11 deletion (c.1708_1728del) and treatment with imatinib 400 mg/day was initiated. Due to disease progression illustrated on baseline versus follow-up ${ }^{18}$ F-FDG-PET/CT scans therapy was switched to imatinib $800 \mathrm{mg} /$ day and later to sunitinib $50 \mathrm{mg} /$ day. Upon further disease progression 10 months later, third line treatment with regorafenib $160 \mathrm{mg} /$ day was initiated. ${ }^{18} \mathrm{~F}-\mathrm{FDG}-\mathrm{PET} / \mathrm{CT}$ showed the metabolic responses after 4 months regorafenib treatment ranging from complete response to the appearance of a new lesion in the liver. The new hypermetabolic lesion was only seen on the non-attenuation-corrected images because of breathing motion artifact.
\end{abstract}

Conclusion: This case illustrates that metabolic response can occur in GIST lesions without morphological response after third line regorafinib treatment. Furthermore this is the first case in literature to show regorafinib response on PET.

Keywords: GIST, ${ }^{18}$ F-FDG-PET/CT, Regorafenib, Follow-up, Attenuation-artefact, Respiratory motion, Case report

\section{Background}

Gastro-intestinal stromal tumors (GISTs) are the most common mesenchymal tumors of the gastro-intestinal tract. However they are very rare, accounting for about $1 \%$ of the tumors of the gastro-intestinal tract. These tumors originate from the interstitial cells of Cajal or other common cell precursors which express tyrosine kinase receptors (type III). They are sometimes called the pacemaker cells of the gut. Treatment consists of surgical resection with or without

\footnotetext{
* Correspondence: Donatienne.vanweehaeghe@uzleuven.be

${ }^{1}$ Nuclear Medicine, University Hospitals Leuven, Herestraat 49, 3000 Leuven, Belgium

Full list of author information is available at the end of the article
}

adjuvant/neo-adjuvant therapy with an oral multikinase inhibitor like regorafinib [1-3].

Regorafenib is an oral multi-kinase inhibitor used to treat metastatic GISTs after progression on standard treatment. It significantly improve progression-free survival compared with placebo in patients [3]. To our knowledge this is the first case in literature to show the response of regorafenib on ${ }^{18} \mathrm{~F}-\mathrm{FDG} \mathrm{PET} / \mathrm{CT}$.

\section{Case presentation}

A 37-year-old male complaining about lower abdominal pain and weight loss was referred to our hospital. He reported a weight loss of $5 \mathrm{~kg}$ in the last 3 months. An abdominal ultrasound and computed tomography (CT) 


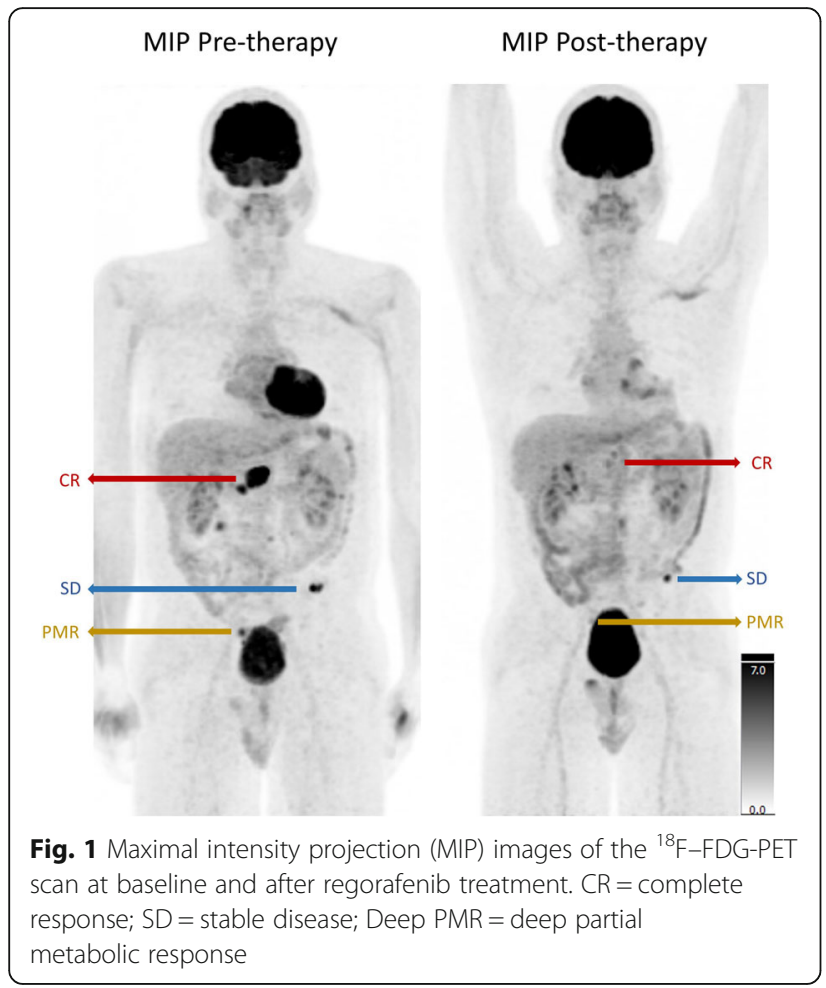

were performed as work-up. Both examinations showed diffuse peritoneal implants.

\section{Discussion}

Surgical exploration and debulking was performed to obtain a tumor specimen for histopathological examination. Histological examination of this specimen showed a GIST with c-KIT exon 11 deletion (c.1708_1728del). As ${ }^{18} \mathrm{~F}-\mathrm{FDG}$ PET has been shown of significant value in evaluating treatment response in GISTs, high dose contrast-enhanced ${ }^{18} \mathrm{~F}-\mathrm{FDG}$ PET/CT scans (374.9 \pm 17.2 $\mathrm{MBq}$; approximately $60 \mathrm{~min}$ after tracer injection) were performed both before treatment and after every therapy switch to evaluate treatment response [4]. ${ }^{18}$ FDG-PET/CT performed for tumor staging showed multiple tumor localizations in the small bowel, the sigmoid and mesenterium without signs of extraabdominal disease. Treatment with imatinib $400 \mathrm{mg}$ daily was started with follow-up ${ }^{18}$ F-FDG PET/CT 2 months later showing disease progression. The dose was increased to $800 \mathrm{mg}$ daily but follow-up ${ }^{18} \mathrm{~F}-\mathrm{FDG}$ PET/ CT 3 months later again revealed disease progression. A switch to sunitinib $50 \mathrm{mg}$ once a day was performed. Upon further disease progression on the ${ }^{18} \mathrm{~F}-\mathrm{FDG} \mathrm{PET} /$ CT 10 months later, third line treatment with regorafenib $160 \mathrm{mg} /$ day was initiated with a mixed response on ${ }^{18} \mathrm{~F}-\mathrm{FDG}-\mathrm{PET} / \mathrm{CT} 4$ months after treatment initiation with regorafinib (Fig. 1). There was one lesion with a complete metabolic response (CR), one with a partial metabolic response (PMR) and one with stable disease (SD) according to the EORTC criteria for ${ }^{18} \mathrm{~F}$-FDG-PET response [5].

Pre- and post-therapy with regorafinib fused PET/CT and CT images with the differences in maximal standardized uptake value $\left(\Delta \mathrm{SUV}_{\text {max }}\right)$ and differences in maximal diameter $\left(\Delta\right.$ diam $\left._{\max }\right)$ are shown in Figs. 2 and 3. The lesion with complete metabolic response had a $\Delta \mathrm{SUV}_{\max }$ of $-91 \%$ and a $\Delta \operatorname{diam}_{\max }$ of $-1.7 \%$. The lesion with the partial metabolic response had a $\Delta \mathrm{SUV}_{\max }$ of $56 \%$ and a $\Delta$ diam $_{\max }$ of $-21 \%$. Both lesions were stable disease on CT scan according to the RECIST1.1 criteria. [6]. The lesion with stable disease on PET had a $\triangle S U V_{\text {max }}$ of $-8.0 \%$ and a $\Delta$ diam $_{\max }$ of $-3.3 \%$. The total volume of the lesion with complete metabolic response was $19.9 \mathrm{~cm}^{3}$

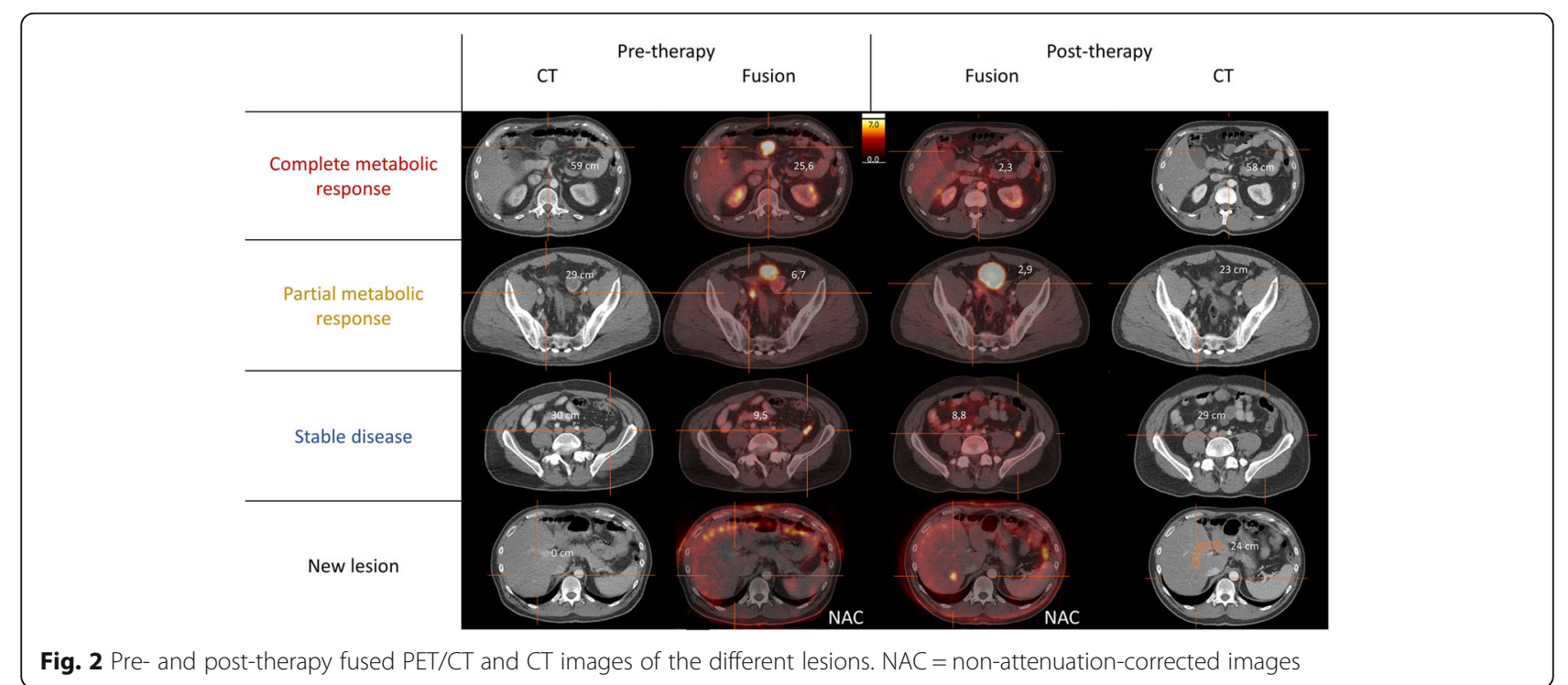




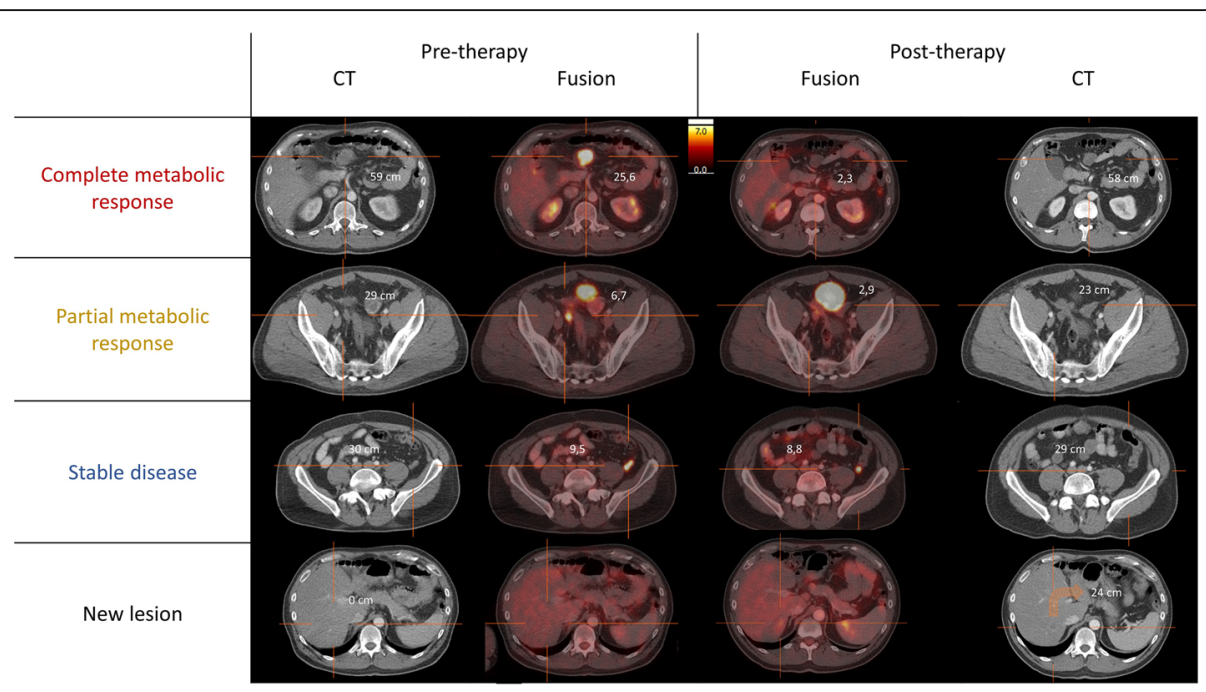

Fig. 3 Pre- and post-therapy fused PET/CT and CT images of the different lesions

pretherapy and $17.6 \mathrm{~cm}^{3}$ posttherapy. The lesions with partial metabolic response and stable disease did not change in volume and were respectively $4.1 \mathrm{~cm}^{3}$ and $3.6 \mathrm{~cm}^{3}$. The volume of the new lesion was $3.2 \mathrm{~cm}^{3}$. No histological confirmation of this new lesion was obtained due to the general condition of the patient. However, this lesion increased both in volume and metabolism on follow-up scans, compatible with a true positive new tumoral lesion.

Besides these previously known lesions, a new hypermetabolic lesion was seen on the non-attenuationcorrected (NAC) ${ }^{18} \mathrm{~F}-\mathrm{FDG}$-PET images. It corresponded to a new hypodense liver lesion on $\mathrm{CT}$, implying a new liver metastasis. However, the lesion was not visible on the attenuation-corrected (AC) and MIP images because of breathing motion-induced misregistration and subsequent lung density attenuation correction, which strongly reduces the apparent uptake in the lesion. This lesion has important consequences for the patient with regard to further treatment options (switch to another tyrosine kinase inhibitor) and illustrates the importance to look at NAC images on all oncological scans, in particular not to miss liver lesions within the liver dome $[7,8]$.

\section{Conclusion}

This case illustrates that metabolic response to third line regorafinib treatment can occur in GIST lesions without morphological response. Therefore, even though it did not affect treatment decision in this case, this finding highlights the importance of ${ }^{18} \mathrm{~F}-\mathrm{FDG}$ PET scans in the evaluation of treatment response in future GIST tumors cases.

\section{Abbreviations}

18F-FDG PET: [18]Fluor-Fluorodeoxyglucose Positron Emission Tomography; AC: Attenuation-corrected; c.1708_1728del: c-KIT exon 11 deletion; CR: Complete metabolic response; CT: Computed tomography; GISTs: Gastrointestinal stromal tumors; MIP: Maximal intensity projection; NAC: Nonattenuation-corrected; PMR: Partial metabolic response; RECIST: Respons Evaluation Criteria in Solid Tumours; SD: Stable disease; $\Delta$ diam $_{\max }$ : Maximal diameter; $\triangle S U V_{\text {max: }}$ Maximal standardized uptake value

\section{Acknowledgements}

We have no acknowledgments to be made.

\section{Funding}

No funding for this case report was received.

\section{Availability of data and materials}

The datasets used and/or analysed during the current study are available from the corresponding author on reasonable request.

\section{Authors' contributions}

All authors contributed to the manuscript in order of publication. DWW contributed to the conception, design, acquisition, analysis and interpretation of data, drafted the manuscript, gave final approve and agreed to be accountable for all aspects of the work. OG: contributed to the conception, design, acquisition, gave final approve and agreed to be accountable for all aspects of the work. W: contributed to the acquisition, gave final approve and agreed to be accountable for all aspects of the work. PS: contributed to the acquisition, gave final approve and agreed to be accountable for all aspects of the work. KVL: contributed to the acquisition, gave final approve and agreed to be accountable for all aspects of the work. CMD: contributed to the conception, design, acquisition, analysis and interpretation of data, has been involved in drafting the manuscript, gave final approve and agreed to be accountable for all aspects of the work.

Ethics approval and consent to participate

This study was approved by the Ethics Committee UZ Leuven. Informed written consent from the patient was received.

\section{Consent for publication}

Written informed consent for publication of their clinical details and/or clinical images was obtained from the patient. A copy of the consent form is available for review by the Editor of this journal. 


\section{Publisher's Note}

Springer Nature remains neutral with regard to jurisdictional claims in published maps and institutional affiliations.

\section{Author details}

'Nuclear Medicine, University Hospitals Leuven, Herestraat 49, 3000 Leuven, Belgium. ${ }^{2}$ Radiology, University Hospitals Leuven, Herestraat 49, 3000 Leuven, Belgium. ${ }^{3}$ Department of oncology, University Hospitals Leuven, Herestraat 49, 3000 Leuven, Belgium.

\section{Received: 23 October 2017 Accepted: 20 February 2018}

Published online: 05 March 2018

\section{References}

1. Maki RG, Blay JY, Demetri GD, Fletcher JA, Joensuu H, Martin-Broto J, et al. Key issues in the clinical Management of Gastrointestinal Stromal Tumors: an expert discussion. Oncologist. 2015;20:823-30.

2. Valsangkar N, Sehdev A, Misra S, Zimmers TA, O'Neil BH, Koniaris LG. Current management of gastrointestinal stromal tumors: surgery, current biomarkers, mutations, and therapy. Surgery. 2015;158:1149-64.

3. Demetri GD, Reichardt P, Kang YK, Blay JY, Rutkowski P, Gelderblom H, et al. Efficacy and safety of regorafenib for advanced gastrointestinal stromal tumours after failure of imatinib and sunitinib (GRID): an international, multicentre, randomised, placebo-controlled, phase 3 trial. Lancet. 2013;381: 295-302.

4. Hassanzadeh-Rad A, Yousefifard M, Katal S, Asady H, Fard-Esfahani A Moghadas Jafari A, et al. The value of (18) F-fluorodeoxyglucose positron emission tomography for prediction of treatment response in gastrointestinal stromal tumors: a systematic review and meta-analysis. J Gastroenterol Hepatol. 2016;31:929-35.

5. Young H, Baum R, Cremerius U, Herholz K, Hoekstra O, Lammertsma AA, et al. Measurement of clinical and subclinical tumour response using [18F]fluorodeoxyglucose and positron emission tomography: review and 1999 EORTC recommendations. European Organization for Research and Treatment of cancer (EORTC) PET study group. Eur J Cancer. 1999:35:1773-82.

6. Eisenhauer EA, Therasse P, Bogaerts J, Schwartz LH, Sargent D, Ford R, et al. New response evaluation criteria in solid tumours: revised RECIST guideline (version 1.1). Eur J Cancer. 2009;45:228-47.

7. Papathanassiou D, Liehn JC, Bourgeot B, Amir R, Marcus C. Cesium attenuation correction of the liver dome revealing hepatic lesion missed with computed tomography attenuation correction because of the respiratory motion artifact. Clin Nucl Med. 2005;30:120-1.

8. $\quad$ Sarikaya I, Yeung HW, Erdi Y, Larson SM. Respiratory artefact causing malpositioning of liver dome lesion in right lower lung. Clin Nucl Med. 2003;28:943-4.

\section{Submit your next manuscript to BioMed Central and we will help you at every step:}

- We accept pre-submission inquiries

- Our selector tool helps you to find the most relevant journal

- We provide round the clock customer support

- Convenient online submission

- Thorough peer review

- Inclusion in PubMed and all major indexing services

- Maximum visibility for your research

Submit your manuscript at www.biomedcentral.com/submit 